\title{
Marine pollution: Let us not forget beach sand
}

\author{
Francois Galgani ${ }^{1}$, Katrin Ellerbrake ${ }^{2}$, Elke Fries ${ }^{2^{*}}$ and Chantal Goreux ${ }^{3}$
}

\begin{abstract}
Background: Assessing the chemical or bacterial contamination in marine waters and sediments is a very common approach to evaluate marine pollution and associated risks. However, toxicity and organic pollution of beach sands have not yet been considered, except in adjacent waters. In the present study, the toxicity and the chemical contamination of natural beach sands collected $20 \mathrm{~m}$ from the shoreline at two sites located on the Mediterranean Sea (Marseille and La Marana, Corsica) were studied.

Results: Up to $16.93 \%$ (net percentage) abnormal or dead larvae was observed in elutriates prepared from the urban beach sand sample (Marseille); no significant toxicity was observed in the sample collected from the reference beach in La Marana. Results of Fourier transform infrared spectroscopy analyses revealed that no microplastics were present in either of the samples. Several polycyclic aromatic hydrocarbons [PAHs] in both samples and a larger number of individual PAHs in the urban sample than in the sample collected from the reference beach were detected. In addition, the antioxidant dioctyldiphenylamine was detected in both beach sand samples, whereby a higher concentration was found in La Marana than in Marseille. Calculated PAH concentrations in elutriates were generally higher than measured ones.
\end{abstract}

Conclusions: The results of this preliminary study provide evidence of toxicity and the presence of organic trace contaminants in beach sands from France. According to our results, monitoring using a combination of biotests and chemical analyses is recommended, especially of sediments from beaches abandoned to urban and industrial areas.

Keywords: oyster larvae biotests, sediments, infrared spectroscopy, gas chromatography-mass spectrometry, microplastics, polycyclic aromatic hydrocarbons, Mediterranean Sea, bioavailability, organic contaminants

\section{Background}

Assessing the chemical or bacterial contamination in marine waters, sediments and organisms is a very common approach to evaluate marine pollution and associated risks [1-7]. In addition, the impact of plastic debris on the chemical contamination of marine ecosystems following the sorption of organic contaminants from seawater or the release of organic plastic additives has been discussed recently [8-10]. Sorption to sediments is the main process that determines the fate of hydrophobic organic compounds in the marine environment. Organic carbon has been shown to be a significant factor in controlling the sorption process [11-13]. Although organic chemicals and heavy metals accumulate in organisms living in/on the sand or on sandy eggs

\footnotetext{
* Correspondence: efries@uni-osnabrueck.de

${ }^{2}$ Institute of Environmental Systems Research, University of Osnabrueck,

Osnabrueck, 49076, Germany

Full list of author information is available at the end of the article
}

$[14,15]$, the contamination of beaches is not normally considered, except in adjacent waters. This might be due to the lower extent of organic materials in beach sediments prone to pollution by organic contaminants. As with many other organic contaminants, some specific compounds, such as anti-UV agents, have been described in marine organisms [16], but not in beach sands, where their occurrence is also expected. Surprisingly, and to our knowledge, no information is available on the toxicity and the presence of organic trace contaminants in natural beaches.

In addition to toxicity tests, the potential for risk may be typically assessed using the proportion of dose estimated to penetrate through exposed skin [17]. However, this approach is still under development. In addition, only recommended values exist for adverse biological effects on organisms living in marine and estuarine sediments $[18,19]$. 
From an environmental perspective, knowledge of the extent to which beaches are contaminated could lead not only to the evaluation of the levels and trends of contaminants, but also, following human contact with sand, to an assessment of the effects on public health. More fundamentally, these measurements should also specify fluxes of contaminants at the interface between coasts and seawater.

In the present study, beach sands were collected from two sites on the Mediterranean Sea in France (Marseille and La Marana, Corsica) and studied for toxicity and chemical pollution. The samples were analysed by Fourier transform infrared [FTIR] spectroscopy to assess the presence of microplastics. Polycyclic aromatic hydrocarbons [PAHs] - a class of hydrophobic organic chemicals - were analysed due to their widespread occurrence and persistence in the environment and their toxic and carcinogenic properties [20] with sufficient evidence from animal studies [21]. PAHs are widely found in surface soils, where typical concentrations range from 5 to $100 \mu \mathrm{g} / \mathrm{kg}$ in forests and 600 to $3,000 \mu \mathrm{g} / \mathrm{kg}$ in urban areas [21]. However, no guidelines on PAHs for beaches or non-industrial soils have ever been described in relation to their effects on human health.

\section{Results}

Biotests

The larval development of the oyster Crassostrea gigas was tested for $24 \mathrm{~h}$, until stage D was reached, in the presence of various concentrations of elutriates prepared from beach sands collected at both sites, Marseille and La Marana (Figure 1). After $24 \mathrm{~h}$, we found up to $16.93 \pm 7.14 \%$ (net percentage, two test series times three replicates each) abnormal or dead larvae in 100\% elutriates prepared from the sediment sample collected in Marseille by seawater extraction. In the sample collected from the reference beach (La Marana), no significant toxicity was observed $(0.87 \pm 0.74 \%$, net percentage, two test series times three replicates each).

\section{FTIR spectroscopy analysis}

FTIR spectroscopy was used to test whether microplastics occur in the beach sands. $\mathrm{CH}_{2}$ groups were found only in the beach sand collected from La Marana. Moreover, no signal was found in this sample after all $\mathrm{CH}_{2}$ groups were removed following extraction using tetrachloromethane.

\section{GC-MS analysis}

Concentrations of PAHs measured in the beach sand samples are shown in Table 1. The following PAHs (including several EPA-PAHs) were detected in the urban sample (Marseille): acenaphthylene [ACY], acenaphthene $[\mathrm{ACE}]$, phenanthrene $[\mathrm{PHE}]$, anthracene $[A N T]$, fluoranthene [FLT], pyrene [PYR], benz(a) anthracene [BAA], chrysene [CHR], benzo(b)fluoranthene $[\mathrm{BBF}]$, benzo(k)fluoranthene [BKF], benzo(e) pyrene [BEP], benzo(a)pyrene [BAP], indeno(1,2,3-cd) pyrene [IPY], dibenz(a,h)anthracene [DBA] and benzo (ghi)perylene $[\mathrm{BPE}]$. The total PAH concentration in the urban sample was $539 \mu \mathrm{g} / \mathrm{kg}$ dry weight [dwt]. The concentrations of individual PAHs were between 1.52 (ACE) and $101 \mu \mathrm{g} / \mathrm{kg}$ dwt (PHE). In the sediment sample collected from La Marana, only three individual PAHs were detected (ACE, BAP, IPY) with a much lower total of $1.56 \mu \mathrm{g} / \mathrm{kg}$ dwt (Table 1$)$.

Concentrations of PAH in elutriates prepared from the sediment samples collected at both sites and in seawater are shown in Table 2. The limits of detection [LOD] are also shown. Since most PAHs in elutriates and seawater used for sediment extraction were below the limits of quantitation [LOQ] and LOD, with the exception of PYR, BAA and CHR in the elutriate prepared from the sediment sample from Marseille, the equilibrium concentrations in the elutriates were calculated. The results are shown in Table 3. The calculated PAH levels in elutriates obtained from the sediment samples in Marseille and La Marana were between 0.07 (DBA) and $426 \mathrm{ng} / \mathrm{L}$ (ACY; sum of PAHs $677 \mathrm{ng} / \mathrm{L})$ and between 0.01 (BAP, IPY) and $4.26 \mathrm{ng} / \mathrm{L}$ (ACY; sum of PAHs $4.28 \mathrm{ng} / \mathrm{L})$, respectively. Since agitation was performed for $8 \mathrm{~h}$, equilibrium could be assumed, and much lower measured PAH concentrations than calculated ones might be attributed to a loss of compounds during elutriate preparation.

Dioctyldiphenylamine - an antioxidant in oils, lubricants, rubber and plastics - was also identified in both samples, whereby the concentration in La Marana (>100 $\mu \mathrm{g} / \mathrm{kg} \mathrm{dwt})$ was higher than that in Marseille $(>0.3 \mu \mathrm{g} / \mathrm{g}$ dwt).

\section{Discussion}

From our study on sand samples collected from two beaches, evidence of toxicity was found in a beach sand aqueous extract. The occurrence of abnormal larvae in the course of larval development in the extract from Marseille could be linked to the occurrence of contaminants in the sediments. The non-specific test is used to measure the overall impact of contaminants. Although the toxicity rate is low compared to immersed sediments from industrial areas or towns [22,23], it is significant and in the same range as some affected areas such as coastal lagoons and bays [24]. It is difficult to draw any conclusions on the basis of these results with regard to the source and nature of the contaminants involved. However, the results suggest the presence of bioavailable toxic contaminants.

Several organic plastic additives, such as phthalates, organotins, bisphenol $\mathrm{A}$ and polybrominated diphenyl 


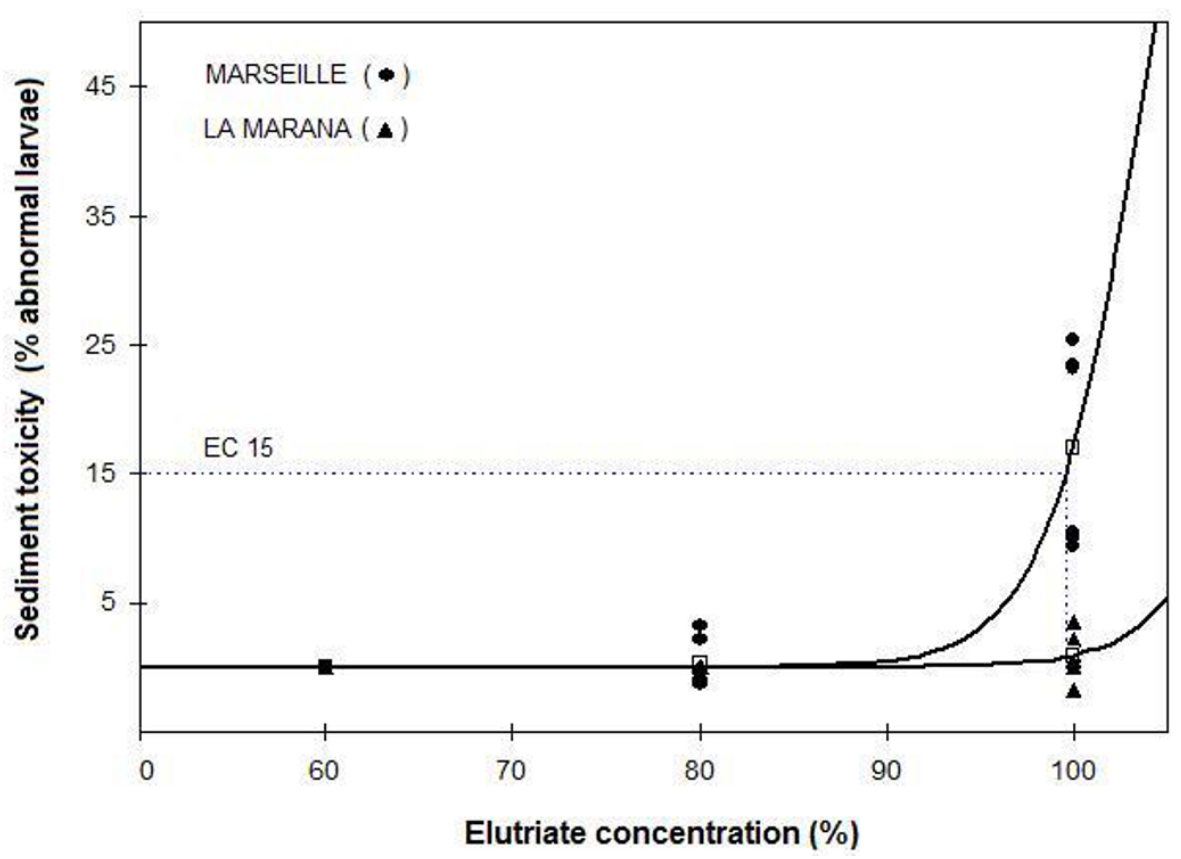

Figure 1 Effects of sand extracts from Marseille and La Marana on larval development of $\boldsymbol{C}$. gigas. Toxicity is expressed as the percentage of abnormal larvae (net percentage, toxicity minus control) after 24-h development in various concentrations of beach sand extracts (elutriates). $\mathrm{EC}_{15}(99.60 \%)$ is the elutriate concentration causing 15\% of abnormalities. Empty squares, mean values; filled circle, Marseille; filled triangle, La Marana.

Table 1 Concentrations of PAHs measured in beach sand samples collected from Marseille and La Marana

\begin{tabular}{|c|c|c|}
\hline Compound & $M(\mu g / k g d w t)$ & LM ( $\mu \mathrm{g} / \mathrm{kg} \mathrm{dwt)}$ \\
\hline NAP & $<\mathrm{LOD}$ & $<\mathrm{LOD}$ \\
\hline $\mathrm{ACY}$ & 61.7 & $<\mathrm{LOD}$ \\
\hline ACE & 1.52 & 0.77 \\
\hline FLN & $<L O D$ & $<\mathrm{LOD}$ \\
\hline PHE & 101 & $<\mathrm{LOD}$ \\
\hline ANT & 4.48 & $<\mathrm{LOD}$ \\
\hline FLT & 61.6 & $<L O D$ \\
\hline PYR & 29.0 & $<L O D$ \\
\hline BAA & 27.5 & $<L O D$ \\
\hline $\mathrm{CHR}$ & 27.4 & $<\mathrm{LOD}$ \\
\hline BBF & 16.3 & $<\mathrm{LOD}$ \\
\hline BKF & 36.0 & $<L O D$ \\
\hline BEP & 37.4 & $<L O D$ \\
\hline BAP & 52.2 & 0.31 \\
\hline IPY & 29.4 & 0.48 \\
\hline DBA & 7.76 & $<L O D$ \\
\hline BPE & 45.6 & $<\mathrm{LOD}$ \\
\hline$\sum \mathrm{PAHS}$ & 539 & 1.56 \\
\hline
\end{tabular}

LOD, limits of detection; M, Marseille; LM, La Marana; SW, seawater; NAP, naphthalene; $A C Y$, acenaphthylene; $A C E$, acenaphthene; FLN, fluorene; $P H E$, phenanthrene; ANT, anthracene; FLT, fluoranthene; PYR, pyrene; BAA, benz(a) anthracene; $\mathrm{CHR}$, chrysene; $\mathrm{BBF}$, benzo(b)fluoranthene; $\mathrm{BKF}$, benzo(k)

fluoranthene; BEP, benzo(e)pyrene; BAP, benzo(a)pyrene; IPY, indeno(1,2,3-cd) pyrene; DBA, dibenz(a,h)anthracene; BPE, benzo(ghi)perylene.
Table 2 Measured concentrations of PAHs in elutriates prepared from beach sand samples and in seawater

\begin{tabular}{lcccc}
\hline Compound & LOD $(\mathbf{n g} / \mathbf{L})$ & $\mathbf{M}(\mathbf{n g} / \mathbf{L})$ & LM $(\mathbf{n g} / \mathbf{L})$ & $\mathbf{S W}$ (ng/L) \\
\hline NAP & 2.25 & $<L O D$ & 2.25 & $<L O D$ \\
ACY & 0.44 & $<L O D$ & 0.44 & $<L O D$ \\
ACE & 0.93 & $<L O D$ & 0.93 & $<L O D$ \\
FLN & 0.46 & $<L O D$ & 0.46 & $<L O D$ \\
PHE & 1.67 & $<L O Q$ & 1.67 & $<L O Q$ \\
ANT & 0.13 & $<L O D$ & 0.13 & $<L O D$ \\
FLT & 5.14 & $<L O Q$ & 5.14 & $<L O Q$ \\
PYR & 0.76 & 6.59 & 0.76 & 6.59 \\
BAA & 0.51 & 1.74 & 0.51 & 1.74 \\
CHR & 0.50 & 2.60 & 0.50 & 2.60 \\
BBF & 0.53 & $<L O D$ & 0.53 & $<L O D$ \\
BKF & 0.53 & $<L O D$ & 0.53 & $<L O D$ \\
BEP & 0.35 & $<L O D$ & 0.35 & $<L O D$ \\
BAP & 0.70 & $<L O D$ & 0.70 & $<L O D$ \\
IPY & 0.57 & $<L O D$ & 0.57 & $<L O D$ \\
DBA & 1.46 & $<L O D$ & 1.46 & $<L O D$ \\
BPE & 1.02 & $<L O D$ & 1.02 & $<L O D$ \\
\hline
\end{tabular}

M, Marseille; LM, La Marana; NAP, naphthalene; ACY, acenaphthylene; ACE, acenaphthene; FLN, fluorene; PHE, phenanthrene; ANT, anthracene; FLT, fluoranthene; PYR, pyrene; BAA, benz(a)anthracene; $C H R$, chrysene; $B B F$, benzo (b)fluoranthene; BKF, benzo(k)fluoranthene; BEP, benzo(e)pyrene; BAP, benzo (a)pyrene; IPY, indeno(1,2,3-cd)pyrene; DBA, dibenz(a,h)anthracene; BPE, benzo (ghi)perylene; $\Sigma P A H s$, summation of polycyclic aromatic hydrocarbons; LOD, limits of detection; LOQ, limits of quantitation. 
Table 3 Calculated equilibrium concentrations of the PAHs in elutriates prepared from beach sand samples

\begin{tabular}{lcc}
\hline Compound & M (ng/L) & LM (ng/L) \\
\hline NAP & - & - \\
ACY & 426 & - \\
ACE & 8.38 & 4.26 \\
FLN & - & - \\
PHE & 170 & - \\
ANT & 6.00 & - \\
FLT & 33.2 & - \\
PYR & 14.3 & - \\
BAA & 2.09 & - \\
CHR & 3.00 & - \\
BBF & 1.16 & - \\
BKF & 2.55 & - \\
BEP & 0.71 & - \\
BAP & 2.41 & 0.01 \\
IPY & 0.42 & 0.01 \\
DBA & 0.07 & - \\
BPE & 0.56 & -28 \\
PPAHs & 677 & - \\
\hline M, & & - \\
\hline
\end{tabular}

M, Marseille; LM, La Marana; SW, seawater; NAP, naphthalene; ACY, acenaphthylene; $A C E$, acenaphthene; FLN, fluorene; PHE, phenanthrene; ANT, anthracene; FLT, fluoranthene; PYR, pyrene; BAA, benz(a)anthracene; CHR, chrysene; $B B F$, benzo(b)fluoranthene; $B K F$, benzo(k)fluoranthene; BEP, benzo(e) pyrene; BAP, benzo(a)pyrene; IPY, indeno(1,2,3-cd)pyrene; DBA, dibenz(a,h) anthracene; $\mathrm{BPE}$, benzo(ghi)perylene; $\Sigma \mathrm{PAHs}$, summation of polycyclic aromatic hydrocarbons

ethers, and chemicals sorbed to plastics, such as PAHs and polychlorinated biphenyls, have potentially toxic or endocrine effects $[9,10,25]$. Migration of such chemicals into elutriates or the direct ingestion of microplastics by oyster larvae followed by leaching into the organisms could be a possible explanation for the observed toxic effect. From our results of FTIR spectroscopy analysis, it can be assumed that $\mathrm{CH}_{2}$ groups in the beach sands were long-chain hydrocarbons and that no plastic polymers were present in beach sands from either of the sampling locations. The absence of microplastics in the sediment samples suggests the existence of bioavailable fractions of organic contaminants in the sediments collected in Marseille.

The detection of PAHs in both sediment samples indicated that beach sands are a possible sink for such hydrophobic chemicals. The occurrence of PAHs in both samples must be due primarily to atmospheric deposition because samples were taken from areas that had not been flooded for some time. Possible PAH emission sources are car and truck traffic, industrial activities using fuel oils and the combustion of coal/ coke (iron and steel industries). In addition, aerosols from the sea may also contribute to the PAH burden in beach sands, especially following stormy weather, as hydrophobic compounds accumulate at the surface, albeit to a lesser extent [26]. The sum of PAH concentrations in the urban sample (Marseille) was within the lower range found in immersed sediments from Marseille Bay, France [7] and Dar es Salaam, Tanzania [3], but higher than in coastal sediments from Togo [5]. In the study by Benlahcen et al. [6], the sum of PAHs was usually higher in Mediterranean coastal sediments than that found in the urban sample of the present study.

$\mathrm{PAH}$ ratios, such as $\mathrm{ANT} /(\mathrm{ANT}+\mathrm{PYR})$ (mass 178), $\mathrm{FLT} /(\mathrm{FLT}+\mathrm{PYR})($ mass 202) and BAA/(BAA + CHR) (mass 228), are commonly used to characterise types of $\mathrm{PAH}$ sources in soils [27] and river sediments [28]. The $\mathrm{ANT} / 178$ ratio of 0.04 calculated for the sediment sample collected in Marseille was lower than 0.1, indicating petrogenic sources. On the other hand, the FLT/202 ratio of 0.7 suggests pyrogenic sources of PAHs, such as kerosene, grass, coal and wood combustion [28,29]. A BAA/228 ratio of 0.5 supports this suggestion [28]. The petrogenic origin of PAHs is unlikely for the selected sampling locations because samples were collected $20 \mathrm{~m}$ from the shoreline where flooding had never occurred. The usefulness of ANT/178 ratio as a recipient matrix has already been called into question before for soil [13,27].

Previous studies on marine sediments and caged mussels $[7,24]$ have demonstrated the different PAH contamination at both sites. Differences in the PAH burden of both samples are explained by the large number of $\mathrm{PAH}$ sources in the Bay of Marseille, including maritime activities, refineries, traffic and urbanisation, whereas the reference station La Marana, which has an adjacent open sea, is unaffected by local sources.

The larger number of individual PAHs and the higher sum of PAHs measured in the urban sediment sample (Marseille) compared to the sample from the reference beach (La Marana) indicate that abnormal or dead oyster larvae may result from bioavailable fractions of PAHs. Toxic effects of PAHs on oyster larvae have been reported for a total elutriate $\mathrm{PAH}$ concentration of 940 ng/L [30]. The total PAH concentration measured in the elutriate obtained from the sample from Marseille was much lower (Table 3). Although the toxic effect was also lower, these results might also indicate effects of other unknown chemicals.

Since the bioavailable fraction of dioctyldiphenylamine is expected to be very low according to the very high estimated octanol-water partition coefficient $\left(\log K_{\text {ow }}\right)$ of 11.26 [31], it is rather unlikely that the observed toxic effect was caused by this compound. However, this nonpolar chemical is not readily biodegradable, suggesting its potential to persist in the environment [31]. Hence, more data on its occurrence in sediments and its bioavailability 
are required. However, other contaminants that could not be detected using the GC-MS methods applied, such as metals or more polar organic compounds, may also be involved.

\section{Conclusions}

This first evidence of toxicity and the presence of organic contaminants, such as PAHs and dioctyldiphenylamine in beach sands, raise important questions that need to be addressed in the future by the scientific community. Further investigations into toxic chemicals in beach sands are recommended in combination with biotests, especially at beaches in the vicinity of urban, industrial and tourist areas. In addition, the question whether aerosols from the sea may be a source of organic pollutants in beach sand should be addressed in future research. The problem of toxicity due to organic contaminants in beach sands will be of broad interest to stakeholders, policymakers and the general public. The abundance of such toxic chemicals as PAHs in beach sand is also of concern from a health perspective since most beaches are frequented by tourists. In addition to providing new insights into marine pollution, evaluating the problem on a larger scale may also help to create a new, simple method of monitoring the state of the environment, environmental quality standards and guidelines.

\section{Methods}

\section{Sampling}

One sand sample made of ten pooled fractions from a $10 \times 10-\mathrm{m}$ area was collected from the top $2 \mathrm{~cm}$ of an urban beach in Marseille (France) and compared with a reference beach in La Marana (Corsica, France). Both sampling locations were $20 \mathrm{~m}$ from the shoreline. Marseille was chosen because it is a large urban, industrial and coastal area with various pollution sources. Marseille and the surrounding area are home to more than $1.2 \times 10^{6}$ inhabitants. The Rhone river delta is adjacent (west) to the city. This is one of the areas affected most severely by contamination in the Mediterranean, especially by PAHs [32]. The sampling location at La Marana was selected as a background station. It is located south of the city Bastia $\left(30 \times 10^{3}\right.$ inhabitants $)$ and has no industry, but tourist activities. Beach sand samples were placed in 100-mL brown glass bottles (Omnilab, Hannover, Germany) precleaned using methanol (HPLC grade, Merck, Darmstadt, Germany) and ultrapure water taken from an Arium 611VF water purification system (Sartorius, Goettingen, Germany). The caps were equipped with Lupolen inserts (Omnilab) wrapped in an aluminium foil. Sediment samples were kept frozen until the chemical analysis was undertaken.

\section{Biotests}

The toxicity of the beach sand samples was assessed using oyster larvae biotests [33]. Sands were agitated for $8 \mathrm{~h}$ after adding filtered seawater (4:1 volume/weight) and decanted for $4 \mathrm{~h}$. Biotests were performed at the Institute Pasteur Lille (IPL), France by exposing oyster embryo larvae to five concentrations of elutriates prepared from both samples $(20 \%, 40 \%, 60 \%, 80 \%$ and $100 \%$ elutriates + control). Elutriates were stored at $+4^{\circ}$ $\mathrm{C}$ until the chemical analysis was undertaken. Mature genitors (C. gigas) were obtained from the Guernsey Sea Farms hatchery. These genitors were carefully cleaned and immersed in unfiltered reference water at $18^{\circ} \mathrm{C}$ for $30 \mathrm{~min}$ before a thermal shock $\left(28^{\circ} \mathrm{C}, 30 \mathrm{~min}\right)$. After the emission of gametes, fecundation was monitored under a microscope; then, after dilution, the larvae were transferred to Iwaki microplates (final volume $3 \mathrm{~mL}$, number 300 larvae/well) and placed in culture with sand extracts at $24 \pm 1^{\circ} \mathrm{C}$ for $24 \mathrm{~h}$. After incubation and after reaching the typical stage D [33], the larvae were fixed in $4 \%$ formaldehyde and decanted. The abnormality rate, including dead larvae, was determined on the basis of a count of 100 larvae/well (two tests, three replicates per concentration). Abnormalities in controls were $6.16 \pm 2.4 \%$. The results are given as the net percentage of abnormalities (toxicity minus toxicity of control The dose/ response relationship was obtained using the REGTOX: macro Excel [34].

\section{FTIR spectroscopy analysis}

Air-dried beach sand samples were analysed using FTIR spectroscopy with an infrared spectrometer and ATR MIRacle (attenuated total reflection; PIKE Technologies, Madison, WI, USA) with a diamond crystal [35]. The system enabled to analyse the surface of the sand for the presence of $\mathrm{CH}_{2}$-related organic compounds or only polymers after tetrachloromethane $\left(\mathrm{CCl}_{4}\right)$ extraction. The depth penetration of light in the samples was $4 \mu \mathrm{m}$. Sensitivity tests were made with pure sand washed with demineralised water and spiked with micronized polyethylene (Total Petrochemicals, Feluy, Belgium). It was checked that $0.01 \%$ and $0.1 \%$ of the micronized polyethylene can be clearly detected.

\section{GC-MS analysis}

The beach sand samples were analysed for the presence of organic contaminants using Soxhlet extraction followed by gas chromatography-mass spectrometry [GCMS]. All sand samples were freeze-dried. To determine the procedural blank, one aliquot (10 g) was precleaned with dichloromethane [DCM] (HPLC grade, Promochem, Wesel, Germany) for $12 \mathrm{~h}$ in a Soxhlet extractor. Aliquots of $10 \mathrm{~g}$ were spiked with $100 \mu \mathrm{L}$ of a deuterated PAH 
standard solution containing acenaphthene- $\mathrm{D}_{10}$, chrysene- $\mathrm{D}_{10}$, perylene- $\mathrm{D}_{12}$ and phenanthrene- $\mathrm{D}_{12}$ (Dr. Ehrenstorfer $\mathrm{GmbH}$, Augsburg, Germany) with a concentration of $5 \mathrm{ng} / \mu \mathrm{L}$ in acetone using an aluminium laboratory spoon. During mixing, contact between the spoon and the solution was strictly avoided. The samples were extracted for $12 \mathrm{~h}$ in the Soxhlet extractor. The solvent was evaporated to dryness and dissolved again in $100 \mu \mathrm{L}$ DCM. Eight microlitres of a standard solution containing fluazifop-butyl (Sigma-Aldrich, Seelze, Germany) in methanol (HPLC grade, Promochem) were added to the final extracts as a recovery standard.

One microlitre of the extracts was injected into a GC injector. GC analyses were performed on a $6890 \mathrm{~N}$ GC system coupled with a 5973 inert mass selective detector (Agilent Technologies, Santa Clara, CA, USA). An HP$5 \mathrm{MS}$ capillary column (5\% diphenyl-95\% dimethylpolysiloxane), $30 \mathrm{~m}$ in length $\times 0.25 \mathrm{~mm}$ in inner diameter and $0.25 \mu \mathrm{m}$ in film thickness (Agilent Technologies), was used for chromatographic separation. The GC programme was as follows: $80^{\circ} \mathrm{C}$ (held for $5 \mathrm{~min}$ ), then at $15^{\circ} \mathrm{C} / \mathrm{min}$ to $180^{\circ} \mathrm{C}$ followed by $5^{\circ} \mathrm{C} / \mathrm{min}$ to $310^{\circ} \mathrm{C}$ (held for $5 \mathrm{~min}$ ). Helium was used as the carrier gas at a flow rate of $1.5 \mathrm{~mL} / \mathrm{min}$. Identification of compounds was carried out by comparing the mass spectrum collected from the Wiley library and retention times and mass spectra to those obtained from the analyses of authentic standards (PAHs were purchased from Neochema, Bodenheim, Germany; dioctyldiphenylamine was purchased from Chemos GmbH, Regenstauf, Germany). Quantification of PAHs was performed by calculating the peak area ratios of the individual PAHs and selected deuterated PAHs corrected by a factor resulting from different recoveries. The procedural blanks for PAHs were between 0.28 (BAA) and $4.04 \mu \mathrm{g} / \mathrm{kg}$ (PHE). The LOD were either determined by blanks or by a peak-to-noise ratio of 3:1. The LOQ were set at three times the LOD.

PAHs were also analysed in elutriates $(7 \mathrm{~mL})$ using solid-phase microextraction and GC-MS. A one-aliquot sample of seawater used for sediment extraction was also analysed. Tap water was analysed as a blank of the whole procedure. Nine microlitres of the deuterated $\mathrm{PAH}$ standard solution with a concentration of $50 \mathrm{pg} /$ $\mu \mathrm{L}$ in acetone was added to the samples as an internal standard. The method was described in detail in Kukucka et al. [36]. The LOD were either determined by blanks or by a peak-to-noise ratio of 3:1. The LOQ were set at three times the LOD.

The equilibrium concentrations of PAHs in elutriates $\left(C_{\mathrm{aq}}\right)$ were calculated using Equation 1:

$$
C_{\mathrm{aq}}=1 / K_{\mathrm{d}} * C_{\mathrm{sed}},
$$

where $K_{\mathrm{d}}$ is the sediment-water distribution coefficient and $C_{\text {sed }}$ is the concentration of the individual PAH in the sediment.

The $K_{\mathrm{d}}$ values were obtained from the organic carbon normalised distribution coefficient $\left(K_{\mathrm{oc}}\right)$ according to Equation 2:

$$
K_{\mathrm{d}}=K_{\mathrm{OC}} * f_{\mathrm{oc}}
$$

where $f_{\text {oc }}$ is the fraction of organic carbon [OC] in the sediment. The mean values of $f_{\mathrm{oc}}(n=3)$ in the samples collected from Marseille and La Marana were determined at $0.05 \pm 0.001 \%$ and $0.002 \pm 0.0001 \%$, respectively, using a total OC analyser (Elementar, Hanau, Germany). According to $\mathrm{Wu}$ and Sun [37], the factor between $K_{\mathrm{d}}$ for seawater and freshwater was 1.21 for PHE. Since no factors exist for the other PAHs, the effect of the saline solution on $K_{\mathrm{d}}$ was neglected.

The $K_{\mathrm{oc}}$ value was determined according to Karickhoff [38] by Equation 3:

$$
\log K_{\mathrm{oc}}=0.989 * \log K_{\mathrm{ow}}-0.346,
$$

where $K_{\mathrm{ow}}$ is the octanol-water partition coefficient. The values of $K_{\text {ow }}$ were taken from Ma et al. [39].

\section{Author details}

${ }^{1}$ Institut français de recherche pour l'exploitation de la mer (Ifremer), Laboratoire Environnement Ressources (LER)/Provence Azur Corse (PAC), Zl Furiani, Bastia, 20200, France ${ }^{2}$ Institute of Environmental Systems Research, University of Osnabrueck, Osnabrueck, 49076, Germany ${ }^{3}$ Total Petrochemicals Research Feluy, Feluy, 7181, Belgium

\section{Authors' contributions}

FG conducted the sampling and biotests. EF and KE analysed the organic trace contaminants, and CG led the IR analyses. All authors read and approved the final manuscript.

\section{Competing interests}

The authors declare that they have no competing interests.

Received: 28 September 2011 Accepted: 20 December 2011 Published: 20 December 2011

\section{References}

1. Claisse D: Chemical contamination of French coasts. The results of a ten years mussel watch. Mar Poll Bull 1989, 20:523-528.

2. Barbee GC, Barich J, Duncan B, Bickham JW, Matson CW, Hintze CJ, Autenrieth RL, Zhou GD, McDonald TJ, Cizmas L, Norton D, Donnelly KC: In situ biomonitoring of PAH-contaminated sediments using juvenile coho salmon (Oncorhynchus kisutch). Ecotoxicol Environ Saf 2008, 71:454-64.

3. Gaspare L, Machiwa JF, Mdachi SJ, Streck G, Brack W: Polycyclic aromatic hydrocarbon $(\mathrm{PAH})$ contamination of surface sediments and oysters from the inter-tidal areas of Dar es Salaam, Tanzania. Environ Pollut 2009, 157:24-34.

4. Fleisher JM, Fleming LE, Solo-Gabriele HM, Kish JK, Sinigalliano CD, Plano L, Elmir SM, Wang JD, Withum K, Shibata T, Gidley ML, Abdelzaher A, He G, Ortega C, Zhu X, Wright M, Hollenbeck J, Backer LC: The BEACHES study: health effects and exposures from non-point source microbial contaminants in subtropical recreational marine waters. Int J Epidemio/ 2010, 39:1291-1298. 
5. Gnandi K, Musa Bandowe BA, Deheyn DD, Porrachia M, Kersten M, Wilcke W: Polycyclic aromatic hydrocarbons and trace metal contamination of coastal sediment and biota from Togo. J Environ Monit 2011, 13:2033-2041.

6. Benlahcen KT, Chaoui A, Budzinski H, Bellocq J, Garrigues Ph: Distribution and sources of polycyclic aromatic hydrocarbons in some Mediterranean coastal sediments. Mar Poll Bull 1997, 34:298-305.

7. Asia L, Mazouz S, Guiliano M, Doumenq P, Mille G: Occurrence and distribution of hydrocarbons in surface sediments from Marseille Bay (France). Mar Poll Bull 2009, 58:424-455.

8. Endo S, Takizawa R, Okuda K, Takada H, Chiba K, Kanehiro H, Ogi H, Yamashita R, Date T: Concentration of polychlorinated biphenyls (PCBs) in beached resin pellets: variability among individual particles and regional differences. Mar Poll Bull 2005, 44:1103-1114.

9. Teuten EL, Saquing JM, Knappe DRU, Barlaz MA, Jonsson S, Björn A, Rowland SJ, Thompson RC, Galloway TS, Yamashita R, Ochi D, Watanuki Y, Moore C, Viet PH, Tana TS, Prudente M, Boonyatumanond R, Zakaria MP, Akkhavong K, Ogata Y, Hirai H, Iwasa S, Mizukawa K, Hagino Y, Imamura A, Saha M, Takada H: Transport and release of chemicals from plastics to the environment and to wildlife. Phil Trans R Soc B 2009, 364:2027-2045.

10. Hirai H, Takada H, Ogata Y, Yamashita R, Mizukawa K, Saha M, Kwan C, Moore C, Gray H, Laursen D, Zettler ER, Farrington JW, Reddy CM, Peacock EE, Ward MW: Organic micropollutants in marine plastics debris from the open ocean and remote and urban beaches. Mar Poll Bull 2011, 62:1683-1692

11. Goring CAl: Control of nitrification by 2-chloro-6-(trichloro-methyl) pyridine. Soil Science 1962, 93:211-218.

12. Goring CAl, Hamaker JW: In Organic Chemicals in the Soil Environment. Volume I. New York: Marcel Dekker Inc.; 1972.

13. Bucheli TD, Blum F, Desaules A, Gustafsson Ö: Polycyclic aromatic hydrocarbons, black carbon, and molecular markers in soils of Switzerland. Chemosphere 2004, 56:1061-1076.

14. Ungherese G, Ugolini A: Sandhopper solar orientation as a behavioural biomarker of trace metals contamination. Environ Poll 2009, 157:1360-1364

15. Vidal M, Domínguez J, Luís A: Spatial and temporal patterns of polycyclic aromatic hydrocarbons (PAHs) in eggs of a coastal bird from northwestern Iberia after a major oil spill. Sci Total Environ 2011, 409:2668-2673.

16. Brown S: Sunscreen wipes out corals. Nature 2008, doi:10.1038/ news.2008.537.

17. Knafla A, Petrovic S, Richardson M, Campbell J, Rowat C: Development and application of a skin cancer slope factor for exposures to benzo[a] pyrene in soil. Regul Toxicol Pharmacol 2011, 59:101-110.

18. Cachot J, Geffard O, Augagneur S, Lacroix S, Le Menach K, Peluhet L, Couteau J, Denier X, Devier M, Pottier D, Budzinski H: Evidence of genotoxicity related to high $\mathrm{PAH}$ content of sediments in the upper part of the Seine estuary (Normandy, France). Aquat Toxicol 2006, 79:257-267.

19. OSPAR: CEMP Assessment Report: 2008/2009 Assessment of Trends and Concentrations of Selected Hazardous Substances in Sediments and Biota. London 2009.

20. Douben PET: PAHs: An Ecotoxicological Perspective (Ecological \& Environmental Toxicology Series) West Sussex: John Wiley \& Sons; 2003.

21. WHO: Health Risks of Persistent Organic Pollutants from Long-range Transboundary Air Pollution. Copenhagen 2003.

22. Dalmazzone C, Blanchet D, Lamoureux S, Durrieu J, Dutrieux E, Camps R, Galgani F: Impact of drilling activities in warm sea: re-colonization capacities of seabed. Oil Gas Sci Technol 2004, 59:625-647.

23. Galgani F, Chiffoleau JF, Orsoni V, Costantini L, Boissery P, Calendini S, Andral B: Chemical contamination and toxicity of sediments from coastal areas of Corsica islands. Chem Ecol 2006, 22:299-312.

24. Galgani F, Senia J, Guillou JL, Laugier T, Munaron D, Andral B, Guillaume B, Coulet $E$, Boissery P, Brun L, Bertrandy MC: Assessment of the environmental quality of French continental Mediterranean lagoons with oyster embryo bioassay. Arch Environ Contam Toxicol 2009, 57:540-551.

25. Fries E, Zarfl C: Sorption of polycyclic aromatic hydrocarbons (PAHs) to low and high density polyethylene (PE). Environ Sci Poll Res 2011, doi: 10.1007/s11356-011-0655-5.
26. Guigue C, Tedetti M, Giorgi S, Goutx M: Occurrence and distribution of hydrocarbons in the surface microlayer and subsurface water from the urban coastal marine area off Marseilles, Northwestern Mediterranean Sea. Mar Poll Bull 2011, doi:10.1016/j.marpolbul.2011.09.013.

27. Brändli RH, Bucheli TD, Ammann S, Desaules A, Keller A, Blum F, Stahel WA: Critical evaluation of PAH source apportionment tools using data from the Swiss soil monitoring network. J Environ Monit 2008, 10:1278-1286.

28. Yunker MB, Macdonald RW, Vingarzan R, Mitchell RH, Goyette D, Sylvestre S: $\mathrm{PAHs}$ in the Fraser River basin: a critical appraisal of $\mathrm{PAH}$ ratios as indicators of PAH source and composition. Org Geochem 2002, 33:489-515.

29. Budzinski H, Jones I, Bellocq J, Piérard C, Garrigues P: Evaluation of sediment contamination by polycyclic aromatic hydrocarbons in the Gironde estuary. Mar Chem 1997, 58:85-97.

30. Geffard O, Geffard A, His E, Budzinski H: Assessment of the bioavailability and toxicity of sediment-associated polycyclic aromatic hydrocarbons and heavy metals applied to Crassostrea gigas embryos and larvae. Mar Poll Bull 2003, 46:481-490.

31. USEPA (United States Environmental Protection Agency): Screening-level Hazard Characterization for High Production Volume Chemicals: Substituted Diphenylamines. Washington, DC 2008

32. Galgani F, Martinez-Gomez C, Giovanardi F, Romanelli G, Calvo M, Caixap J, Cento A, Scarpato A, Benbrahim S, Sammari C, Deudero S, Boulahdid M, Andral B: Assessment of polycyclic aromatic hydrocarbon concentrations in mussels (Mytilus galloprovincialis) from the North West basin of the Mediterranean Sea (the Mylilos project). Environ Monit Assess 2011 172:301-317.

33. His $E$, Seaman M, Beiras R: A simplification of the bivalve embryogenesis larval development bioassay method for water quality assessment. Water Res 1997, 31:351-355.

34. REGTOX. [http://www.normalesup.org/ vindimian/].

35. Coleman PP: Practical Sampling Techniques for Infrared Analysis Boca Raton: CRC Press; 1993

36. Kukucka P, Lammel G, Dvorská A, Klánová J, Möller A, Fries E: Contamination of Antarctic snow by polycyclic aromatic hydrocarbons dominated by combustion sources in the polar region. Environ Chem 2010, 7:504-513.

37. Wu W, Sun H: Sorption-desorption of phenanthrene - effect of nanopores, solute concentration, and salinity. Chemosphere 2010, 81:961-967.

38. Karickhoff SW: Semi-empirical estimation of sorption of hydrophobic pollutants on natural sediments and soils. Chemosphere 1981, 8:833-846

39. Ma Y-G, Lei YD, Xiao H, Wania F, Wang W-H: Critical review and recommended values for the physical-chemical property data of 15 polycyclic aromatic hydrocarbons at $25^{\circ} \mathrm{C}$. J Chem Eng Data 2010, 55:819-825.

doi:10.1186/2190-4715-23-40

Cite this article as: Galgani et al:: Marine pollution: Let us not forget beach sand. Environmental Sciences Europe 2011 23:40.

\section{Submit your manuscript to a SpringerOpen ${ }^{\odot}$ journal and benefit from:}

- Convenient online submission

- Rigorous peer review

- Immediate publication on acceptance

- Open access: articles freely available online

- High visibility within the field

- Retaining the copyright to your article

Submit your next manuscript at $>$ springeropen.com 